\title{
The Future of Democracy and Space: Increased Democratization of Governmental Decision Making
}

\author{
Kathleen M. Connell \\ Principal ${ }^{*}$ \\ The Connell Whittaker Group, LLC, San Diego, CA 92122
}

\begin{abstract}
[Abstract]. NASA's lack of a direct constituency among voters creates a structural issue that constrains budgets and options for civil space. In the first decade of the twenty-first century, trends have emerged that may alter how space policy is created. The future of space policy may well evolve into a more open system, thus impacting NASA's budget and programs. Mass collaboration, IT tools and Web 2.0 have empowered individuals. Space entrepreneurs are likely to create a new class of space consumers. Space assets are on the critical path of global warming. Taken together, these trends promise to involve the global and national public more directly, and more often, in space policy choices.
\end{abstract}

\section{NASA's Structural Political Position: The Absence of a Major Direct Constituency Base}

NASA, for all of its visibility and iconic meaning to society, does not possess a large direct constituency base in the American population. It is unlike other well-known and well-funded government and quasi-government programs and agencies, such as the Department of Housing and Urban Development, the Veterans Administration, the Small Business Administration, Medicare, The Department of Education, The U.S. Postal Service or the Department of Defense. These and other federal entities provide direct economic payouts, subsidies, loans, benefits, services and goods to individual Americans, their families and communities. These Americans, in turn, are political constituents, and delivering direct economic and social benefits to a constituent base is crucial to election and reelection bids of elected officials.

For this reason, NASA's budget and priorities seem destined to be circumscribed and set by a small group of space policy actors. For better or worse, NASA is generally not impacted by the massive membership lobbies that are engaged in the business of steering benefits to their members via legislation. These organizations, along with Political Action Committees, hold the leverage of constituent votes and campaign funds for elected officials within their grasp.

A case in point is the American Association of Retired Persons (AARP), which has a membership of 38 million members and a large lobbying budget. It is a major player in Medicare and the health industry in general. ${ }^{1}$ Likewise, veterans represent approximately 27 million taxpayers and their families. In contrast, AIAA, the largest aerospace professional society in the U.S., claims 31,000 enrolled members. From this perspective, it is easy to understand why structural issues in our representative democracy continue to contain the small budget wedge of the largely popular civil space program, and are likely to do so in the future.

Further, if perception is reality in politics, not since the Cold War have Americans perceived unquestionable benefit from NASA. Most of the American voters have been either structurally excluded, or have not been incentivised since the Apollo era, to engage in space policy when budget season rolls around each year.

How then, will public space investment meet its needs in competition with other domestic and foreign priorities? A related question is, how can NASA build a new, crewed spacecraft capable of lunar exploration, as well as maintain its portfolio of space science and other activities within its current budget? These questions and debates now consume the space community, NASA Administrators, Congress and space supporters alike. ${ }^{2}$ To answer these questions from a structural perspective means that a "perfect storm" of new trends must emerge. These trends might include:

- An increase in the number of voters who have a direct interest in space expenditures;

- The emergence of another national space emergency to drive up the space budget;

- More engagement from public in space policy budget advocacy choices via volunteerism;

* Principal, The Connell Whittaker Group, LLC, San Diego, California, AIAA Member. 
- Discovery of additional capital infusions for space projects from other sources.

. The following discussion briefly outlines how these emergent structural changes can be viewed.

\title{
II. Structural Shift \#1: From Localized Space Constituent to Global Space Consumer
}

\author{
"The free market is the only mechanism that has ever been discovered for achieving participatory democracy." \\ — Milton Friedman, Economist
}

NASA policies are proposed by each Administration, and disposed of by Congressional legislation. Beneath this super structure for decision-making in space policy is a traditional set of players and intermediatiries with direct interest in the policy and budget outcomes at NASA. These historic space players are generally understood to align in the categories of industry, academia, technical associations and the military. Rarely discussed, but equally important, is the role of unions, which represent a key percentage of the public and private sector space workforce.

In addition, it is sometimes argued that large aerospace Political Action Committees (PAC) are ghost drivers of space policy. While the private sector is unquestionably influential, facts and outcomes would suggest that it does not hold dominion in space matters. The evidence for this is that NASA's budget has climbed only incrementally over time. Second, the top all-time PAC contributors to office holders show aerospace firms are $35^{\text {th }}$ on the list, well below unions, realtors, bankers, brewers and Microsoft.

More interesting is the very large budget impact of very local space worker constituents, and their power in the traditional space states of Texas, Florida, Alabama Maryland and California. For purposes of this discussion, it is assumed that the very localized, regional space states - home to NASA Centers and jobs - drive many major budget decisions at NASA and in Congress today. These locales are a very small percentage of the American political base, but a historically powerful one. That power is about to be shared with a new class of space consumers, created by space entrepreneurship.

This author also contends that American voters, even those who do not live next door to a NASA center, are about to be transformed into relatively more empowered space consumers. The means for this is the privatization ${ }^{3}$ of space travel, and the increasing need and consumption of critical goods and services from space assets. The requirements of investment dictate that this must be so, for investment requires customers in order to generate a return. Individuals and blocks of consumers are now poised to be customers for many commercial space firms.

The rise of the consumer and consumer movements ${ }^{4}$ in America is well documented in every industrial sector, but only recently has migrated to the space sector. With consumption comes choice. Soon, space consumers may be "voting" with their discretionary income on space services and goods, registering stockholder initiatives, and applying pressure on firms via government regulation. The much-anticipated arrival of space consumers on the private space scene is not yet a fact, but their potential impact is worth noting now.

\section{Structural Shift \#2: The Rise of Proactive Citizen Space Hives}

\author{
"We've put a lot of time into this, and we do believe the study will have an impact. Think of this as an opening salvo in a \\ long-term strategy, a long-term campaign." \\ -Jeff Krukin, Executive Director, Space Frontier Foundation \\ (On release of White Paper critical of NASA's Crew Exploration Vehicle) ${ }^{5}$
}

\begin{abstract}
"I write this to everyone who wonders why the subject of space exploration is of any real importance to them. Most of us know about NASA and that they have a budget of over \$16 Billion annually, and most of us know that anything launched into space is usually hideously expensive and many times can result in a mission failure. By now you would have heard that NASA intends to go to the Moon again in 2018 but why should that interest you? You already have enough concerns here in your life on earth with things like terrorism, hurricanes, wars and your own employment prospects keeping you up at night...(Editor). The list is practically endless. I'm not going to sweep all these things aside and tell you that space is more important when you say, "Why is space so important to me?" Or " What has space got to do with my life here and now?"
\end{abstract}

—Fred Stratford, Blogger, http://www.redcolony.com

Twenty-first century space policy is also being dramatically influenced in a direct manner by technology. Social IT tools now enable fundraising, blogging, advocacy, instant information, texting, Web 2.0 sharing, meet-ups, myspace.com friends, community building and instant advocacy. To confirm this, anyone can open Google and type 
in the search term "space exploration" and the search engine will return 71 million hits. Many, if not most, are independent "netizens," who are creating new information, or passing on official space media releases with editorial comments.

This "Army of Davids", is inconceivable to those accustomed to the institutional Goliath language of space discourse, where, only a few years ago, senior experts were the only voices heard. Equally interesting is, not only the quantity of space opinion and political action on the web, but also the quality of the public information publicly. "Billions and Billions" (to borrow a well-known quote from Carl Sagan) no longer refers just to the firmament of stars, but also to the number of global citizens now in the know, and talking online $24 / 7$, about all manner of space subjects.

Savvy activists and organizers are using these virtual tools, and more sophisticated advocacy IT platforms, to create communities that mobilize new publics, interest groups, space "prosumers," $\dagger$ beleaguered space scientists with dwindling budgets, and others. Several thousand of these interested parties and organizations have been cataloged in informal databases and in a Directory of Space Actors. ${ }^{7}$ The list of active space networks represents official organizations, industry lobbies, professional societies, informal societies, bloggers, affiliative networks, state-based organizations, consultants, researchers, and media. What it does not fully capture is a profusion of subniche players with enormous reach. Recently, the smaller organizations have begun uniting in big-tent coalitions, as is common in grassroots movements since the beginning of modern society and social movements.

In 1994, Kevin Kelly, founder of Wired magazine, captured this phenomena in the notion of "hives," where independent agents spontaneously form to meet group objectives. Kelly viewed this trend as a neo-biological social and economic development. ${ }^{8}$ Both lead and leaderless hives of concerns parties can now be mobilized in short order to make major impacts on space budgets, and to provide highly competent input into the space policy process.

Added to this is the evolution of gaming to simulation, as Second Life ${ }^{9}$ and other quasi-virtual environments allow for a simulated high-definition space experience for anyone with an adequate computer. These tools are evolvable, and most importantly, free or very low cost.

In political terms, interested persons can now "opt-in" to the space policy debate, click and send their opinion and requests to elected officials and the media, and host meet-ups in Congressional offices with their representatives. Many more are choosing to do so in increasing numbers. As theorists and practitioners in space policy know, the impact on official legislation and Administration policy is already happening.

The structural shift that these technologies allow has already changed political strategy from a closed system to a more open process, in the very campaigns of the electeds who will go to Washington to decide space and other budget matters. Technology has also become personal, and reflecting this, a participatory space movement aligns itself with private space investments. A space leader articulated the change during a recent interview: "the shift is from watching others go into space, to 'I want to go.",10

As a result, independent and hive space actors are no longer relegated to a marginal status in decision making about space exploration and utilization of space assets for the public good and goods.

As heady as these trends have become, in terms of current space policy, in a representative democracy the general public is still largely kept unaware of the specialist discussions of policy. The myth of "rocket science" still discourages most citizens from being enfranchised with regard to the space sphere.

The fear of anarchy may rouse many orderly space engineers to dread this smorgasbord of public engagement. However, given the web and other forms of interaction, there is less reason to doubt that, sooner rather than later, space will be demystified for the general public once and for all. It is clear that a solid plank has been thrown across the moat that once separated the "wiki" community ${ }^{11}$ from the rocket community. Transit and conversation into each other's domains has begun and will continue in a free society.

\section{Structural Shift \#3: From Civil Space As A Luxury to Space Assets as A Necessity in Global Warming Mitigation} “That's the difference between governments and individuals. Governments don't care, individuals do.”
-Mark Twain

"If global emissions of carbon dioxide continue to rise at the rate of the past decade, this research shows that there will be disastrous effects, including increasingly rapid sea level rise, increased frequency of droughts and floods, and increased stress on wildlife and plants due to rapidly shifting climate zones."

\footnotetext{
†"Prosumer" is a term coined by Futurist Alvin Toffler. It denotes a new class of producing consumers.
} 
Some in space circles have advanced a theory that the NASA budget is small because space is a luxury, compared to other budget priorities. As this author has suggested, space policy is better understood in the context of our political structure. If there was ever truth to the luxury argument, now global warming has changed the meaning of space for society.

Global warming has become the most compelling new societal issue of the era. Today, space finds itself on the critical path of halting global warming and its potential of mass extinctions. Both NASA and NOAA budgets account for a significant percentage of climate change research and assets. Both agencies advance the state of knowledge regarding global warming and provide crucial satellite data that assist during larger and longer weather crises, such as hurricanes.

On the political front, almost overnight, former Vice President Al Gore and the world's top scientists, persuaded a global majority of the existence of global warming. As of this writing, the momentum of voters towards climate change as an issue is still gaining strength, and will be felt in the 2008 Presidential election.

One influential blogger watchdog in the green consumer constituency, a growing voter block, is full of informed candor and alarm in his published views of the state of affairs in space policy, orbiting space assets and global warming:

1. Malfunction: The nation's earth-observing satellites, which are critical to an increasingly important array of environmental initiatives, are in "crisis." That's the assessment of the American Association for the Advancement of Science. Within five years, we could lose $40 \%$ of the sensors aboard these satellites, according to National Research Council. We're talking hurricane research, climate studies. You know, the future of the planet stuff.

2. Misdirection: While President Bush is pushing for goals like a new moon landing and mission to Mars, NASA quietly last year erased part of its mission: "To understand and protect our home planet." Consistent with that view, its earth science budget was slashed by almost one third.

3. Muffling: It's a wonder that any quality earth science research has been done, given those conditions. But it has. Director of the Goddard Institute For Space Studies, James Hansen has emerged as a rock star in the environmental community for speaking clearly and authoritatively about global warming. Despite the best efforts of his handlers. Lately, Hansen has been among those pointing out that many of the dire warnings outlined in the latest United Nations report on climate change are proving a tad conservative. In other words, the world is moving faster than thought toward a frightening future."

—Dan Shapley, http://www.thedailygreen.com, August 2, 2007

Such worry in the green community and the earth science community will eventually find its way to Capitol Hill in the form of advocacy. The proposed legislative restorations to the current NASA budget, underway in both the House and the Senate, signal that the message has been received. The net effect will be to heighten the focus on the very visible NASA. This time, the issues and demands on the civil space sector are almost science fiction made science fact. This author contents that NASA will be expected to play a leading role in the drama of saving the planet and humanity from extinction.

Forward-thinking space planners have begun heralding the importance of merging the space community with the green community, for direct societal benefit and to avoid a collision of interest, now and going forward.

Space is also plotted on other points of the critical path for humanity. One opportunity is in global warming mitigation via energy delivery from advanced technology satellites in space. Another is in the now, real question of spacecraft-as-lifeboat. Will climate degradation force us to explore space? These and other topics require more space community engagement and focus now, in order to fully comprehend the issues and opportunities in space.

\section{Conclusion}

Taken as whole, these observations about possible future outcomes and space policy scenarios are timely, given the increasing relevance of space activities, climate change, space-based energy and economic development. The structural issues that drive space policy are still in place, but giving way to a new wave of democracy-seeking trends. This indicates that change is underway in democratic institutions. The old citadel of space policy is evolving to include a commonwealth of highly-motivated and empowered players. The opportunity exists to further understand the intersections of public will, policy, interactive technology, space commercialization and global warming, as these issues move to center stage in the policy process.

Finally, it is important to note, that social science research, including public policy and astrosociology, provides an intellectual meeting place in the space community (Pass 2004a, 2004b), ${ }^{13}$ where these societal issues can and must be researched and discussed. The development of the long-ignored social sciences as a single, inter- 
disciplinary field will allow collaboration among colleagues in a more organized manner, and will allow for the development of a single, easily-recognizable and accessible body of knowledge for both scholars and practioners. Those who elect to become applied astrosociologists will be able to act with increased competence and assure that timely action is taken to address the challenges and opportunities before us all.

\section{References}

\footnotetext{
1 Pindell, J.W., “AARP joins \$60m effort to set candidates' agenda," The Boston Globe [online newspaper], URL: www.boston.com/news/nation/articles/2007/06/24/aarp joins 60m effort to set candidates agenda/, June 24, 2007.

2 Planetary Society, "Save Our Science," Planetary.org [online website], URL: http://www.planetary.org/programs/projects/sos, February 14, 2007.

${ }^{3}$ Belfiore, M., Rocketeers, Smithsonian Books, New York, NY, 2006.

${ }^{4}$ Gabriel, Y., and Lang, T., The Unmanageable Consumer, Sage Publications, London, 1995.

5 David, L., "Space Advocates seek NASA Course Correction," MSNBC.com [online website], URL: http://www.msnbc.msn.com/id/14012996/, July 24, 2006.

${ }^{6}$ Reynolds, G., An Army of Davids, Nelson Current, Nashville, TN, 2006, Chapter 11.

${ }^{7}$ Unknown Author, "Directory of Space Actors," Excel Spreadsheet, 2006.

${ }^{8}$ Kelly, K., Out of Control: The New Biology of Machines, Social Systems and the Economic World, William Patrick Books, United States of America, 1994.

${ }^{9}$ Linden Lab, URL: http://www.secondlife.com.

${ }^{10}$ Danty, M. and Connell, K.M., The Legacy of Apollo: Enduring Gifts to Humanity [film], 2006.

11 Tapscot, D. and Williams, A.D., Wikinomics: How Mass Collaboration Changes Everything, Penguin Group, New York, NY, 2006, Chapter 10.

${ }^{12}$ Hansen, J., NASA Goddard Institute for Space Studies, "Research Finds that Earth's Climate is Approaching Dangerous Point" [Press Release], Mission to Humanity.com [online website], URL: http://www.missiontohumanity.com, May 31, 2007.

13 Pass, J., "Inaugural Essay: The Definition and Relevance of Astrosociology in the Twenty-First Century (Part One: Definition, Theory and Scope), Astrosociology.com Virtual Library [online archive], URL: Hhttp://www.astrosociology.com/Library/Iessay/iessay_p1.pdfH, 2004 [cited 6 August 2007].
} 